\title{
Efficacy of Semaglutide in a Subcutaneous and an Oral Formulation
}

\author{
Juris J. Meier* \\ Diabetes Center Bochum-Hattingen, St. Josef-Hospital, Ruhr-University Bochum, Bochum, Germany
}

\section{OPEN ACCESS}

Edited by:

Gaetano Santulli,

Columbia University, United States

Reviewed by:

Bo Ahrén,

Lund University, Sweden

Jochen Seufert,

University of Freiburg, Germany

*Correspondence:

Juris J. Meier

juris.meier@rub.de

Specialty section:

This article was submitted to

Clinical Diabetes,

a section of the journal

Frontiers in Endocrinology

Received: 23 December 2020

Accepted: 08 March 2021

Published: 25 June 2021

Citation:

Meier JJ (2021) Efficacy of

Semaglutide in a Subcutaneous

and an Oral Formulation.

Front. Endocrinol. 12:645617.

doi: 10.3389/fendo.2021.645617
Despite the benefits of early and effective glycemic control in the management of type 2 diabetes (T2D), achieving glycated hemoglobin $\left(\mathrm{HbA}_{1 \mathrm{c}}\right)$ targets is challenging in some patients. Glucagon-like peptide-1 receptor agonists (GLP-1RAs) provide effective reductions in $\mathrm{HbA}_{1 \mathrm{c}}$ and body weight. Semaglutide is the only GLP-1RA that is available in both an injectable and oral formulation. The efficacy of once-weekly subcutaneous semaglutide and once-daily oral semaglutide has been investigated in the global SUSTAIN and PIONEER phase III clinical trial programs in a range of clinical settings, including early T2D managed with diet and exercise only, more established T2D uncontrolled on one to three oral antidiabetic drugs, and advanced disease treated with insulin. Across the SUSTAIN program, once-weekly subcutaneous semaglutide $1.0 \mathrm{mg}$ reduced $\mathrm{HbA}_{1 \mathrm{c}}$ by $1.5-1.8 \%$ after $30-56$ weeks, which was significantly more than sitagliptin, liraglutide, exenatide extended release, dulaglutide, canagliflozin, or insulin glargine. Across the PIONEER program, once-daily oral semaglutide $14 \mathrm{mg}$ reduced $\mathrm{HbA}_{1 \mathrm{c}}$ by $1.0-1.4 \%$, significantly more than sitagliptin or empagliflozin, and to a similar extent as liraglutide after 26 weeks. In addition, subcutaneous semaglutide reduced body weight significantly more than all active comparators tested, while oral semaglutide reduced body weight more than sitagliptin and liraglutide, and to a similar extent as empagliflozin. Neither formulation of semaglutide has been associated with an increased risk of hypoglycemia and both improve various measures of health-related quality of life. Semaglutide offers the benefits of a highly effective GLP-1RA in both injectable and oral formulations. Selection of the most appropriate formulation can be made on an individual basis to best suit the patient's preferences and needs.

Keywords: body weight, glycated hemoglobin $\left(\mathrm{HbA}_{1 \mathrm{c}}\right)$, efficacy, glucagon-like peptide-1 receptor agonist (GLP-1RA), oral, semaglutide, subcutaneous, type 2 diabetes

\footnotetext{
Abbreviations: Cana, canagliflozin; $\mathrm{C}_{\text {avg, }}$, median semaglutide concentration; DTSQ, Diabetes Treatment Satisfaction Questionnaire; Dula, dulaglutide; Empa, empagliflozin; ER, extended release; Exe, exenatide; GLP-1RA, glucagon-like peptide-1 receptor agonist; $\mathrm{HbA}_{10}$, glycated hemoglobin; IGlar, insulin glargine; Lira, liraglutide; Met, metformin; OAD, oral antidiabetic drug; OD, once daily; OW, once weekly; Pbo, placebo; PIONEER, Peptide InnOvatioN for the Early diabEtes tReatment; s.c., subcutaneous; Sema, semaglutide; SF-36, 36-item Short-Form; SGLT2i, sodium-glucose co-transporter-2 inhibitor; Sita, sitagliptin; SU, sulfonylurea; SUSTAIN, Semaglutide Unabated Sustainability in Treatment of Type 2 Diabetes; T2D, type 2 diabetes; TZD, thiazolidinedione.
} 


\section{INTRODUCTION}

Evidence from trials and real-world studies in patients with type 2 diabetes (T2D) indicates that the risk of complications may be reduced by providing sustained glycemic control and that nearnormal glycated hemoglobin $\left(\mathrm{HbA}_{1 \mathrm{c}}\right)$ levels should be achieved as early as possible in the T2D trajectory $(1,2)$. However, achieving and sustaining optimum glycemic control remains challenging in many patients (3), despite treatment advances and the availability of new classes of glucose-lowering agents. In a recent study of 28,315 patients with incident $\mathrm{T} 2 \mathrm{D}$, around half of patients spent the 10 years after diagnosis with $\mathrm{HbA}_{1 \mathrm{c}}$ above desired targets: mean percent time spent with $\mathrm{HbA}_{1 \mathrm{c}} \geq 7 \%$ was $40 \%$ in the first 2 years and $61 \%$ after $6-10$ years (3).

Reasons that may be responsible for the lack of improvement in glucose levels over time include failure to address the complex pathophysiology of T2D, therapeutic inertia leading to delayed treatment intensification, insufficient implementation of lifestyle changes, and poor adherence to and persistence with treatment $(4,5)$. Most patients should receive metformin initially, but if control is suboptimal after 3-6 months, treatment intensification with another glucose-lowering therapy is required, and selection of subsequent therapies should be made on an individualized basis to meet the specific needs of the patient (4).

Glucagon-like peptide-1 receptor agonists (GLP-1RAs) are a well-established class of glucose-lowering agents that induce glucose-mediated stimulation of insulin secretion, reduce glucagon release, reduce hepatic glucose output, delay gastric emptying, increase satiety, and improve cardiovascular risk factors (6-9). By correcting multiple pathophysiological defects in T2D, GLP-1RAs provide effective glycemic control, with a low risk of hypoglycemia, while reducing body weight, blood pressure, and in some cases, cardiovascular events (6).

Semaglutide is the only GLP-1RA that is available in both an injectable and an oral formulation (10). Once-weekly subcutaneous semaglutide was approved by the US Food and Drug Administration in December 2017 (11) and by the European Medicines Agency in February 2018 (12), while once-daily oral semaglutide was approved in the US in September 2019 (13) and in Europe in April 2020 (14). It was thought that an oral formulation may improve convenience, acceptance, and adherence with GLP1RA therapy, and may provide an additional option to help increase glycemic target achievement, particularly in patients who are reluctant to initiate injectable medications (10).

This article describes results from global clinical trial programs that established the efficacy of subcutaneous and oral semaglutide in a range of clinical settings and discusses factors that may influence the choice of formulation in individual patients. The safety of subcutaneous and oral semaglutide will be covered in a separate article in this issue (15).

\section{DESIGN OF THE SUSTAIN AND PIONEER PROGRAMS}

Both formulations of semaglutide were investigated in comprehensive international clinical development programs.
As part of the Semaglutide Unabated Sustainability in Treatment of Type 2 Diabetes (SUSTAIN) program, the efficacy of once-weekly subcutaneous semaglutide was evaluated in over 7,000 patients in six global phase IIIa trials (SUSTAIN 1-6) across the wide spectrum of the T2D disease course (16-21) and in nearly 3,000 patients in four phase IIIb trials (SUSTAIN 7-10) (22-25) (Table 1). Oral semaglutide was then investigated in eight global Peptide InnOvatioN for the Early diabEtes tReatment (PIONEER) phase IIIa trials in over 8,000 patients, with similarly broad evaluation in different patient populations who were receiving a range of background medications (26-33) (Table 1). Further SUSTAIN and PIONEER trials were conducted in Japanese subjects and are not described in detail here.

Patients with early T2D (mean diabetes duration 3-4 years) managed on diet and exercise only were studied in SUSTAIN 1 and PIONEER $1(16,27)$. Effects in patients with more established T2D (mean diabetes duration 7-10 years) already receiving one to three oral antidiabetic drugs (OADs) and in need of treatment intensification were studied in seven SUSTAIN trials and four PIONEER trials $(17-19,22-25,28-30,33)$. Patients with advanced disease (mean diabetes duration 13-15 years) on insulin who required additional treatment were studied in SUSTAIN 5 and PIONEER $8(20,26)$. Typical inclusion criteria for the SUSTAIN and PIONEER trials were age $\geq 18$ years, a diagnosis of T2D at least 90 days prior to screening, and inadequate glycemic control within a specified $\mathrm{HbA}_{1 \mathrm{c}}$ range (Table 1).

In both trial programs, initial dose escalation of semaglutide was implemented to mitigate gastrointestinal adverse events. The SUSTAIN trials assessed final once-weekly doses of $1.0 \mathrm{mg}$ only, or $0.5 \mathrm{mg}$ and $1.0 \mathrm{mg}$, of subcutaneous semaglutide (16-25). Oncedaily doses of oral semaglutide ( $14 \mathrm{mg}$ only or $3 \mathrm{mg}, 7 \mathrm{mg}$, and 14 $\mathrm{mg}$ ) were assessed in most trials in the PIONEER program (26-32); however, the $3 \mathrm{mg}$ dose is not approved as a maintenance dose and data are not included here. PIONEER 7 evaluated a flexible dosing approach by which the oral semaglutide dose was adjusted ( $3 \mathrm{mg}, 7$ $\mathrm{mg}$, or $14 \mathrm{mg}$ ) depending on the patient's glycemic response and gastrointestinal tolerability, to mimic the individualized approach that may be used in clinical practice (33).

Once-weekly subcutaneous semaglutide was compared with placebo $(16,24)$, as well as commonly used glucose-lowering agents from drug classes recommended for patients who require further treatment intensification: the dipeptidyl peptidase- 4 inhibitor sitagliptin (17); other GLP-1RAs (exenatide extended release [ER], dulaglutide and liraglutide) $(18,22,25)$; the sodium-glucose co-transporter-2 inhibitor (SGLT2i) canagliflozin (23); and basal insulin (insulin glargine) (19). In the PIONEER program, four trials compared once-daily oral semaglutide with the active comparators sitagliptin, the SGLT2i empagliflozin, and liraglutide (28-30, 33).

Across the SUSTAIN program, the primary and confirmatory secondary endpoints for most trials were change from baseline in $\mathrm{HbA}_{1 \mathrm{c}}$ and body weight, respectively, to the end of treatment (30, 40,52 , or 56 weeks) (16-25). In the PIONEER program, most trials had the primary and confirmatory secondary endpoints at week 26 of change from baseline in $\mathrm{HbA}_{1 \mathrm{c}}$ and body weight, 
TABLE 1 | Summary of the designs of the global glycemic efficacy SUSTAIN and PIONEER trials (16-26).

\begin{tabular}{|c|c|c|c|c|}
\hline Trial & Treatment arms & Key inclusion criteria & $\begin{array}{l}\text { Trial duration; } \\
\text { blinding }\end{array}$ & Primary endpoint \\
\hline \multicolumn{5}{|c|}{ Trials in early T2D (mean duration 3-4 years) } \\
\hline $\begin{array}{l}\text { SUSTAIN } 1 \\
(N=388)\end{array}$ & $\begin{array}{ll}\text { - } & \text { S.c. semaglutide } 0.5 \mathrm{mg} \mathrm{OW} \\
\text { - } & \text { S.c. semaglutide } 1.0 \mathrm{mg} \mathrm{OW} \\
\text { - } & \text { Placebo OW }\end{array}$ & $\begin{array}{l}\text { - } \quad \text { Treated with diet and exercise } \\
\text { - } \mathrm{HbA}_{1 \mathrm{c}} 7.0-10.0 \%\end{array}$ & 30 weeks; blinded & $\begin{array}{l}\text { Change in } \mathrm{HbA}_{1 \mathrm{c}} \text { from baseline } \\
\text { to week } 30\end{array}$ \\
\hline $\begin{array}{l}\text { PIONEER } 1 \\
(N=703)\end{array}$ & $\begin{array}{ll}\text { - } & \text { Oral semaglutide } 3 \text { mg OD } \\
\text { - } & \text { Oral semaglutide } 7 \text { mg OD } \\
\text { - } & \text { Oral semaglutide } 14 \text { mg OD } \\
\text { - } & \text { Placebo OD }\end{array}$ & $\begin{array}{l}\text { - } \quad \text { Treated with diet and exercise } \\
\text { - } \quad \mathrm{HbA}_{1 \mathrm{c}} 7.0-9.5 \%\end{array}$ & 26 weeks; blinded & $\begin{array}{l}\text { Change in } \mathrm{HbA}_{1 \mathrm{c}} \text { from baseline } \\
\text { to week } 26\end{array}$ \\
\hline \multicolumn{5}{|c|}{ Trials in established T2D (mean duration 6-10 years) } \\
\hline $\begin{array}{l}\text { SUSTAIN } 2 \\
(N=1,231)\end{array}$ & $\begin{array}{ll}\text { - } & \text { S.c. semaglutide } 0.5 \mathrm{mg} \mathrm{OW} \\
\text { - } & \text { s.c. semaglutide } 1.0 \mathrm{mg} \mathrm{OW} \\
\text { - } & \text { Sitagliptin } 100 \mathrm{mg} \mathrm{OD}\end{array}$ & $\begin{array}{l}\text { - } \quad \text { Treated with met, TZD, or both } \\
\mathrm{HbA}_{1 \mathrm{c}} 7.0-10.5 \%\end{array}$ & 56 weeks; blinded & $\begin{array}{l}\text { Change in } \mathrm{HbA}_{1 \mathrm{c}} \text { from baseline } \\
\text { to week } 56\end{array}$ \\
\hline $\begin{array}{l}\text { PIONEER } 3 \\
(N=1,864)\end{array}$ & $\begin{array}{ll}\text { - } & \text { Oral semaglutide } 3 \mathrm{mg} O \mathrm{OD} \\
\text { - } & \text { Oral semaglutide } 7 \mathrm{mg} \text { OD } \\
\text { - } & \text { Oral semaglutide } 14 \mathrm{mg} \text { OD } \\
\text { Sitagliptin } 100 \mathrm{mg} O \mathrm{OD}\end{array}$ & $\begin{array}{ll}\text { - } & \text { Treated with met } \pm \mathrm{SU} \\
\text { - } & \mathrm{HbA}_{1 \mathrm{c}} 7.0-10.5 \%\end{array}$ & 78 weeks; blinded & $\begin{array}{l}\text { Change in } \mathrm{HbA}_{1 \mathrm{c}} \text { from baseline } \\
\text { to week } 26\end{array}$ \\
\hline $\begin{array}{l}\text { PIONEER } 7 \\
(N=504)\end{array}$ & $\begin{array}{l}\text { - Oral semaglutide (flexible dose } \\
\text { adjustment: } 3,7 \text {, or } 14 \mathrm{mg} \text { ) OD } \\
\text { - Sitagliptin } 100 \mathrm{mg} \mathrm{OD}\end{array}$ & $\begin{array}{l}\text { - Treated with 1-2 from met, TZD, SU, } \\
\text { SGLT2i } \\
\text { - } \mathrm{HbA}_{1 \mathrm{c}} 7.5-9.5 \%\end{array}$ & $\begin{array}{l}52 \text { weeks; open- } \\
\text { label }^{*}\end{array}$ & $\begin{array}{l}\text { Proportion of patients with } \mathrm{HbA}_{1 \mathrm{c}} \\
<7.0 \% \text { at week } 52\end{array}$ \\
\hline $\begin{array}{l}\text { SUSTAIN } 3 \\
(N=813) \\
\text { SUSTAIN } 7 \\
(N=1,201)\end{array}$ & $\begin{array}{ll}\text { - } & \text { S.c. semaglutide } 1.0 \mathrm{mg} \mathrm{OW} \\
\text { - } & \text { Exenatide ER } 2.0 \mathrm{mg} \mathrm{OW} \\
\text { - } & \text { s.c. semaglutide } 0.5 \mathrm{mg} \mathrm{OW} \\
\text { - } & \text { s.c. semaglutide } 1.0 \mathrm{mg} \mathrm{OW} \\
\text { - } & \text { Dulaglutide } 0.75 \mathrm{mg} \mathrm{OW} \\
& \text { Dulaglutide } 1.5 \mathrm{mg} \mathrm{OW}\end{array}$ & $\begin{array}{ll}\text { - } & \text { Treated with 1-2 from met, SU, TZD } \\
\text { - } & \mathrm{HbA}_{1 \mathrm{c}} 7.0-10.5 \% \\
\text { - } & \text { Treated with met } \\
\text { - } & \mathrm{HbA}_{1 \mathrm{c}} 7.0-10.5 \%\end{array}$ & $\begin{array}{l}56 \text { weeks; open- } \\
\text { label } \\
40 \text { weeks; open- } \\
\text { label }\end{array}$ & $\begin{array}{l}\text { Change in } \mathrm{HbA}_{1 \mathrm{c}} \text { from baseline } \\
\text { to week } 56 \\
\text { Change in } \mathrm{HbA}_{1 \mathrm{c}} \text { from baseline } \\
\text { to week } 40\end{array}$ \\
\hline $\begin{array}{l}\text { SUSTAIN } 10 \\
(N=577) \\
\text { PIONEER } 4 \\
(N=711)\end{array}$ & $\begin{array}{ll}\text { - } & \text { s.c. semaglutide } 1.0 \mathrm{mg} \mathrm{OW} \\
\text { - } & \text { Liraglutide } 1.2 \mathrm{mg} \mathrm{OD} \\
\text { - } & \text { Oral semaglutide } 14 \mathrm{mg} \mathrm{OD} \\
\text { - } & \text { Liraglutide } 1.8 \mathrm{mg} \mathrm{OD} \\
\text { - } & \text { Placebo OD }\end{array}$ & $\begin{array}{ll}\text { - } & \text { Treated with 1-3 from met, SU, SGLT2i } \\
\text { - } & \mathrm{HbA}_{1 \mathrm{c}} 7.0-11.0 \% \\
\text { - } & \text { Treated with met } \pm \text { SGLT2i } \\
\text { - } & \mathrm{HbA}_{1 \mathrm{c}} 7.0-9.5 \%\end{array}$ & $\begin{array}{l}30 \text { weeks; open- } \\
\text { label } \\
52 \text { weeks; blinded }\end{array}$ & $\begin{array}{l}\text { Change in } \mathrm{HbA}_{1 \mathrm{c}} \text { from baseline } \\
\text { to week } 30 \\
\text { Change in } \mathrm{HbA}_{1 \mathrm{c}} \text { from baseline } \\
\text { to week } 26\end{array}$ \\
\hline $\begin{array}{l}\text { SUSTAIN } 9 \\
(N=302)\end{array}$ & $\begin{array}{l}\text { - } \quad \text { S.c. semaglutide } 1.0 \mathrm{mg} \mathrm{OW} \\
\text { - } \quad \text { Placebo OW }\end{array}$ & $\begin{array}{ll}\text { - } & \text { Treated with SGLT2i } \pm \text { (met or SU) } \\
\text { - } & \mathrm{HbA}_{1 \mathrm{c}} 7.0-10.0 \%\end{array}$ & 30 weeks; blinded & $\begin{array}{l}\text { Change in } \mathrm{HbA}_{1 \mathrm{c}} \text { from baseline } \\
\text { to week } 30\end{array}$ \\
\hline $\begin{array}{l}\text { SUSTAIN } 8 \\
(N=788)\end{array}$ & $\begin{array}{l}\text { - } \quad \text { s.c. semaglutide } 1.0 \mathrm{mg} \mathrm{OW} \\
\text { - } \quad \text { Canagliflozin } 300 \mathrm{mg} \mathrm{OD}\end{array}$ & $\begin{array}{ll}\text { - } & \text { Treated with met } \\
\text { - } & \mathrm{HbA}_{1 \mathrm{c}} 7.0-10.5 \%\end{array}$ & 52 weeks; blinded & $\begin{array}{l}\text { Change in } \mathrm{HbA}_{1 \mathrm{c}} \text { from baseline } \\
\text { to week } 52\end{array}$ \\
\hline $\begin{array}{l}\text { PIONEER } 2 \\
(N=822)\end{array}$ & $\begin{array}{l}\text { - } \quad \text { Oral semaglutide } 14 \text { mg OD } \\
\text { - } \quad \text { Empagliflozin } 25 \text { mg OD }\end{array}$ & $\begin{array}{l}\text { - } \quad \text { Treated with met } \\
\text { - } \mathrm{HbA}_{1 \mathrm{c}} 7.0-10.5 \%\end{array}$ & $\begin{array}{l}52 \text { weeks; open- } \\
\text { label }\end{array}$ & $\begin{array}{l}\text { Change in } \mathrm{HbA}_{1 \mathrm{c}} \text { from baseline } \\
\text { to week } 26\end{array}$ \\
\hline $\begin{array}{l}\text { SUSTAIN } 4 \\
(N=1,089)\end{array}$ & $\begin{array}{ll}\text { - } & \text { S.c. semaglutide } 0.5 \mathrm{mg} \mathrm{OW} \\
\text { - } & \text { S.c. semaglutide } 1.0 \mathrm{mg} \mathrm{OW} \\
\text { - } & \text { Insulin glargine OD }\end{array}$ & $\begin{array}{l}\text { - } \quad \text { Treated with met } \pm \text { SU } \\
\text { - } \mathrm{HbA}_{1 \mathrm{c}} 7.0-10.0 \%\end{array}$ & $\begin{array}{l}30 \text { weeks; open- } \\
\text { label }\end{array}$ & $\begin{array}{l}\text { Change in } \mathrm{HbA}_{1 \mathrm{c}} \text { from baseline } \\
\text { to week } 30\end{array}$ \\
\hline \multicolumn{5}{|c|}{ Trials in advanced T2D (mean duration $13-15$ years) } \\
\hline $\begin{array}{l}\text { SUSTAIN } 5 \\
(N=397)\end{array}$ & $\begin{array}{ll}\text { - } & \text { s.c. semaglutide } 0.5 \mathrm{mg} \mathrm{OW} \\
\text { - } & \text { S.c. semaglutide } 1.0 \mathrm{mg} \mathrm{OW} \\
\text { - } & \text { Placebo OW }\end{array}$ & $\begin{array}{ll}\text { - } & \text { Treated with basal insulin } \pm \text { met } \\
\text { - } & \mathrm{HbA}_{1 \mathrm{c}} 7.0-10.0 \%\end{array}$ & 30 weeks; blinded & $\begin{array}{l}\text { Change in } \mathrm{HbA}_{1 \mathrm{c}} \text { from baseline } \\
\text { to week } 30\end{array}$ \\
\hline $\begin{array}{l}\text { PIONEER } 8 \\
(N=731)\end{array}$ & $\begin{array}{ll}\text { - } & \text { Oral semaglutide } 3 \mathrm{mg} \text { OD } \\
\text { - } & \text { Oral semaglutide } 7 \mathrm{mg} \text { OD } \\
\text { - } & \text { Oral semaglutide } 14 \mathrm{mg} \text { OD } \\
\text { - } & \text { Placebo OD }\end{array}$ & $\begin{array}{l}\text { - Treated with basal, basal-bolus, or } \\
\text { premixed insulin } \pm \text { met } \\
\text { - } \mathrm{HbA}_{1 \mathrm{c}} 7.0-9.5 \%\end{array}$ & 52 weeks; blinded & $\begin{array}{l}\text { Change in } \mathrm{HbA}_{1 \mathrm{c}} \text { from baseline } \\
\text { to week } 26\end{array}$ \\
\hline $\begin{array}{l}\text { PIONEER } 5 \\
(N=324)\end{array}$ & $\begin{array}{l}\text { - } \text { Oral semaglutide } 14 \text { mg OD } \\
\text { - } \quad \text { Placebo OD }\end{array}$ & $\begin{array}{l}\text { - } \text { Moderate renal impairment } \\
\text { - Treated with met or SU, or both, or basal } \\
\text { insulin } \pm \text { met } \\
\text { - } \mathrm{HbA}_{1 \mathrm{c}} 7.0-9.5 \%\end{array}$ & 26 weeks; blinded & $\begin{array}{l}\text { Change in } \mathrm{HbA}_{1 \mathrm{c}} \text { from baseline } \\
\text { to week } 26\end{array}$ \\
\hline
\end{tabular}

*With 52-week extension study.

ER, extended release; $\mathrm{HbA}_{1 c}$, glycated hemoglobin; met, metformin; N, number of randomized patients; OD, once daily; OW, once weekly; s.c., subcutaneous; SGLT2i, sodium-glucose co-transporter-2 inhibitor; sita, sitagliptin; SU, sulfonylurea; T2D, type 2 diabetes; TZD, thiazolidinedione.

respectively (26-32). An exception was PIONEER 7, in which the primary endpoint was the proportion of patients achieving $\mathrm{HbA}_{1 \mathrm{c}}<7.0 \%$ at week 52 (33).

The effects of semaglutide were investigated in certain special populations. SUSTAIN 6 and PIONEER 6 assessed the effects of semaglutide vs. placebo on cardiovascular outcomes in patients with T2D at high risk of cardiovascular events $(21,32)$, and are discussed in a separate article (34). The PIONEER 5 trial was conducted to explore the efficacy and safety of oral semaglutide $14 \mathrm{mg}$ vs. placebo in patients with T2D (most commonly at an advanced stage) and moderate renal impairment (estimated glomerular filtration rate of $30-59 \mathrm{~mL} / \mathrm{min}$ per $1.73 \mathrm{~m}^{2}$ ) (31). 
In the SUSTAIN program, analyses were performed on data obtained before the initiation of any rescue medication or before premature treatment discontinuation (16-25). The PIONEER program adopted a different approach, with two scientific questions related to the efficacy objectives being addressed through the definition of two estimands (35). The primary estimand was the treatment policy estimand, presented here, which evaluated the treatment effect for all randomized patients regardless of trial product discontinuation or use of rescue medication. The trial product estimand evaluated the treatment effect, assuming that all patients remained on the trial product for the entire planned trial duration and did not use rescue medication.

\section{HBA $_{1 C}$ REDUCTIONS WITH SEMAGLUTIDE}

Results for $\mathrm{HbA}_{1 \mathrm{c}}$ reductions from baseline are shown in Figure 1. It should be noted that the SUSTAIN and PIONEER trials differed in their inclusion criteria (e.g., baseline $\mathrm{HbA}_{1 \mathrm{c}}$ and background medication), duration, and analysis approach, therefore the magnitude of $\mathrm{HbA}_{1 \mathrm{c}}$ reduction cannot be directly compared.

\section{Patients with Early T2D Being Treated With Diet and Exercise}

In trials of patients with early $\mathrm{T} 2 \mathrm{D}$ insufficiently controlled with diet and exercise alone, who had baseline $\mathrm{HbA}_{1 \mathrm{c}}$ levels of $8.0-8.1 \%$, the highest doses of subcutaneous semaglutide $(1.0 \mathrm{mg})$ or oral semaglutide $(14 \mathrm{mg}$ ) given as monotherapy were able to reduce $\mathrm{HbA}_{1 \mathrm{c}}$ by $1.6 \%$ (at 30 weeks) and $1.4 \%$ (at 26 weeks), respectively, and were superior to placebo (both $p<0.001$ ) (Figure 1A) $(16,27)$.

\section{Patients With Established T2D Being Treated With One to Three OADs}

Considerable $\mathrm{HbA}_{1 \mathrm{c}}$ reductions (1.0-1.6\%) were seen with semaglutide in patients with established T2D who were already receiving one to two OADs in SUSTAIN 2 (metformin \pm a thiazolidinedione) and PIONEER 3 (metformin \pm a sulfonylurea) (Figure 1B) $(17,29)$. In these trials, subcutaneous semaglutide $(0.5$ $\mathrm{mg}$ and $1.0 \mathrm{mg}$ over 56 weeks) and oral semaglutide $(7 \mathrm{mg}$ and $14 \mathrm{mg}$ over 26 weeks) reduced $\mathrm{HbA}_{1 \mathrm{c}}$ significantly more than the active comparator, once-daily sitagliptin $100 \mathrm{mg}$ (all $p<0.001$ ) $(17,29)$. A similar result was observed when flexibly dosed oral semaglutide was compared with sitagliptin over 52 weeks in PIONEER 7 ( -1.3 vs. $-0.8 \%$; $p<0.001$ ) (Figure 1B) (33).

When compared with other GLP-1RAs in patients with established T2D already receiving one to three OADs, subcutaneous semaglutide $1.0 \mathrm{mg}$ reduced $\mathrm{HbA}_{1 \mathrm{c}}$ significantly more than once-weekly exenatide ER $2.0 \mathrm{mg}(-1.5 \%$ vs. $-0.9 \%)$, once-weekly dulaglutide $1.5 \mathrm{mg}(-1.8 \%$ vs. $-1.4 \%)$, and oncedaily liraglutide $1.2 \mathrm{mg}(-1.7 \%$ vs. $-1.0 \%)$ (all $p<0.001)(18,20$, 25) (Figure 1B). With oral semaglutide, similar $\mathrm{HbA}_{1 \mathrm{c}}$ reductions were seen as with once-daily liraglutide $1.8 \mathrm{mg}$ when patients were on a background of metformin \pm an SGLT2i in PIONEER 4 (-1.2\% vs. $-1.1 \%)$ (30).
When added to an SGLT2i \pm metformin or sulfonylurea, subcutaneous semaglutide reduced $\mathrm{HbA}_{1 \mathrm{c}}$ by $1.5 \%$ compared with $0.1 \%$ with placebo $(p<0.001)$ at 30 weeks in SUSTAIN 9 (Figure 1C) (24). When compared with SGLT2i as second-line therapy, subcutaneous semaglutide $1.0 \mathrm{mg}$ reduced $\mathrm{HbA}_{1 \mathrm{c}}$ significantly more than canagliflozin $300 \mathrm{mg}$ after 52 weeks $(-1.5 \%$ vs. $-1.0 \%$; $p<0.001)$, while oral semaglutide $14 \mathrm{mg}$ reduced $\mathrm{HbA}_{1 \mathrm{c}}$ significantly more than empagliflozin $25 \mathrm{mg}$ after 26 weeks $(-1.3 \%$ vs. $-0.9 \%$; $p<0.001)$ (Figure 1C) $(23,28)$. Subcutaneous semaglutide has also been compared with basal insulin. In SUSTAIN 4, in patients uncontrolled on metformin \pm a sulfonylurea, subcutaneous semaglutide $0.5 \mathrm{mg}$ and $1.0 \mathrm{mg}$ produced greater $\mathrm{HbA}_{1 \mathrm{c}}$ reductions than insulin glargine over 30 weeks $(-1.2 \%$ and $-1.6 \%$ vs. $-0.8 \%$; both $p<0.0001)$ (19).

\section{Patients With Advanced T2D}

For patients with advanced uncontrolled T2D already receiving insulin, subcutaneous semaglutide $(0.5 \mathrm{mg}$ and $1.0 \mathrm{mg})$ and oral semaglutide (7 mg and $14 \mathrm{mg}$ ) both reduced $\mathrm{HbA}_{1 \mathrm{c}}$ significantly more than placebo $(p<0.001)$ (Figure 1D) $(20,26)$. In SUSTAIN 5, insulin dose decreased from baseline to week 30 with subcutaneous semaglutide $0.5 \mathrm{mg}$, semaglutide $1.0 \mathrm{mg}$, and placebo (geometric means from 39.3 to 35.4 , from 37.4 to 31.5 , and from 36.6 to 35.2 IU, respectively) (20). In PIONEER 8 , total daily insulin dose significantly decreased from baseline to week 26 with oral semaglutide $7 \mathrm{mg}$ and $14 \mathrm{mg}$ compared with placebo (-8 IU and -9 IU vs. -1 IU; both $p<0.001$ ) (26).

In patients with mean T2D duration of 14 years and with moderate renal impairment in PIONEER 5, oral semaglutide $14 \mathrm{mg}$ was significantly more effective than placebo in reducing $\mathrm{HbA}_{1 \mathrm{c}}$ at 26 weeks $(-1.0 \%$ vs. $-0.2 \% ; p<0.001)$ (Figure 1D) (31).

\section{Achievement of Glycemic Targets}

For both formulations, effective $\mathrm{HbA}_{1 \mathrm{c}}$ reductions allowed the majority of patients to achieve glycemic targets. In the SUSTAIN program, $66-80 \%$ achieved $\mathrm{HbA}_{1 \mathrm{c}}<7 \%$ with subcutaneous semaglutide $1.0 \mathrm{mg}$, while $55-77 \%$ achieved $\mathrm{HbA}_{1 \mathrm{c}}<7 \%$ with oral semaglutide $14 \mathrm{mg}$ in the PIONEER program (16-20, 2231, 33).

\section{BODY WEIGHT REDUCTIONS WITH SEMAGLUTIDE}

\section{Patients With Early T2D Being Treated With Diet and Exercise}

In patients with early $\mathrm{T} 2 \mathrm{D}$, subcutaneous semaglutide $1.0 \mathrm{mg}$ and oral semaglutide $14 \mathrm{mg}$ monotherapy were able to reduce body weight by $4.5 \mathrm{~kg}$ and $3.7 \mathrm{~kg}$, respectively, which were superior to the reductions seen with placebo (1.0 and $1.4 \mathrm{~kg}$, respectively) $(p<0.001)$ (Figure $2 \mathrm{~A})(16,27)$.

\section{Patients With Established T2D Being Treated With One to Three OADs}

In the SUSTAIN 2, PIONEER 3, and PIONEER 7 trials in patients with established $\mathrm{T} 2 \mathrm{D}$ receiving one or two OADs, subcutaneous 
A

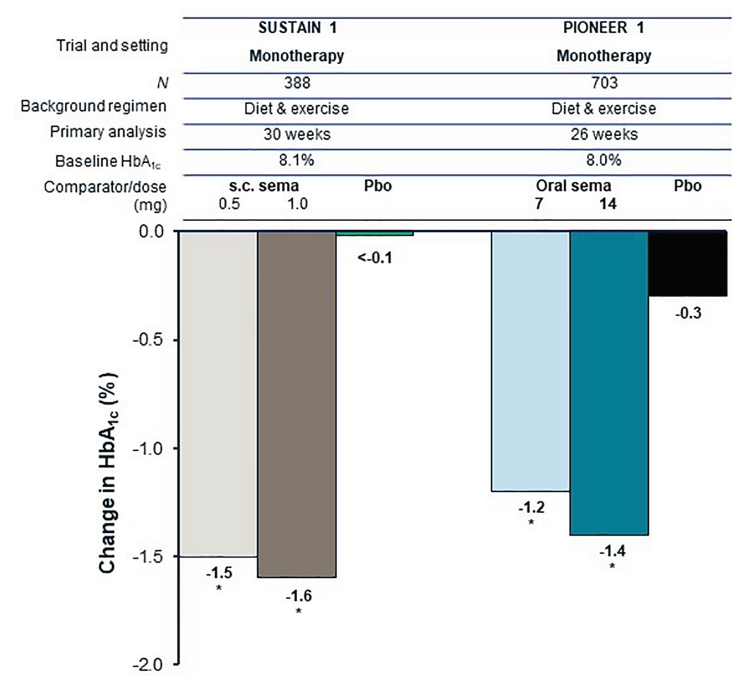

B

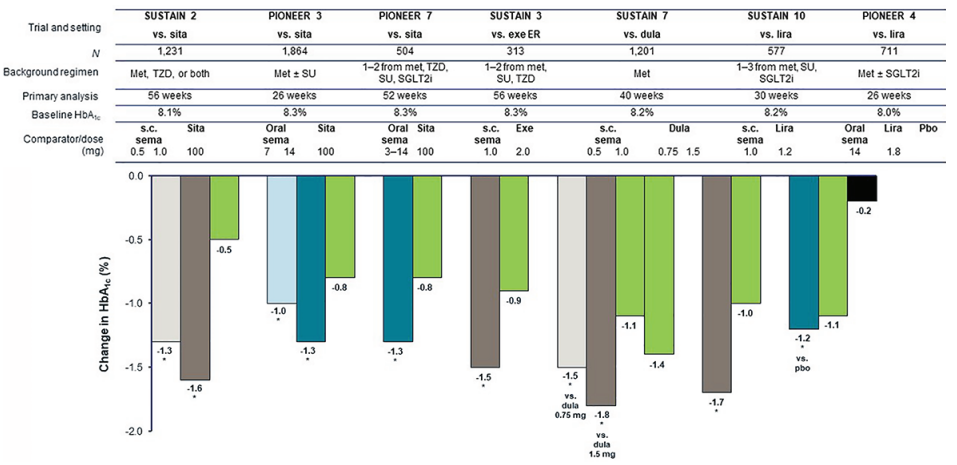

C

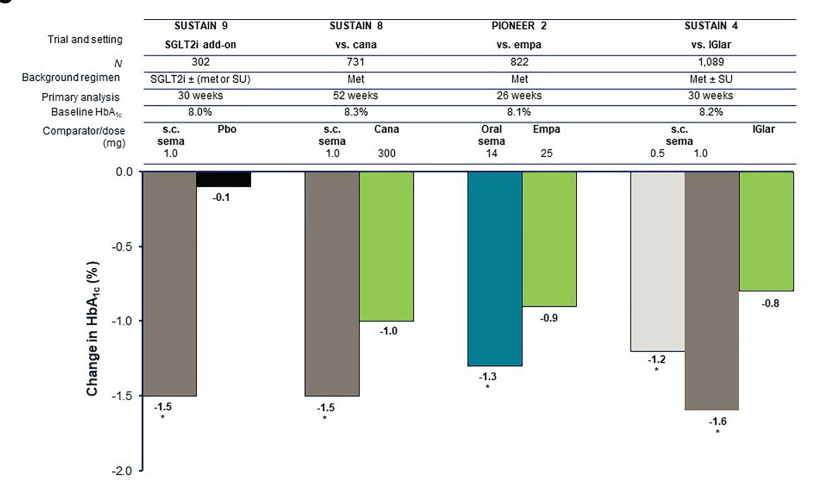

D

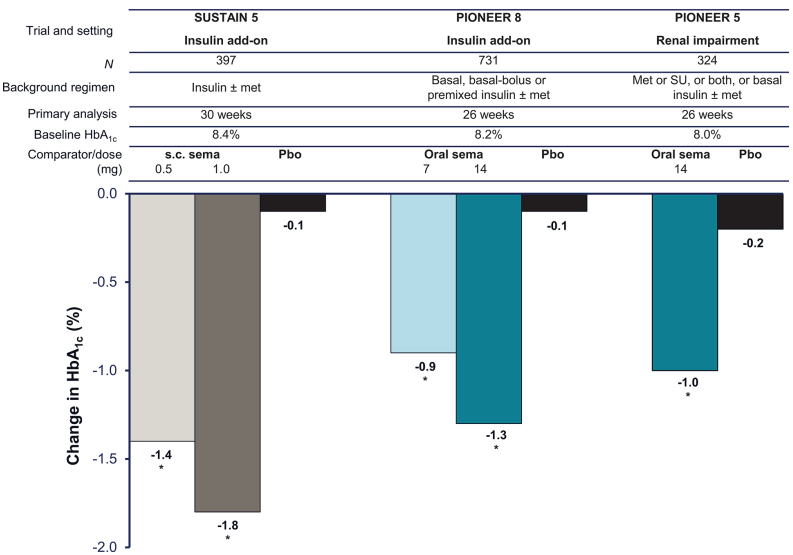

FIGURE 1 | Reduction in $\mathrm{HbA}_{1 \mathrm{c}}$ with semaglutide and comparators in global glycemic efficacy trials (16-20, 22-26, 31, 33). (A) Trials in early T2D (mean duration 3-4 years). (B) Trials in established T2D (mean duration 6-10 years) with incretin-based therapies as comparators. (C) Trials in established T2D (mean duration 6-10 years) with other comparators. (D) Trials in advanced T2D (mean duration 13-15 years). For the SUSTAIN trials shown, HbA 1 r reduction at study end (weeks 30, 40, 52, or 56) was the primary endpoint. Estimated mean changes from baseline in $\mathrm{HbA}_{1 \mathrm{c}}$ included only data obtained before initiation of any rescue medication or before premature treatment discontinuation. For the PIONEER trials shown, $\mathrm{HbA}_{1 \mathrm{c}}$ reduction at week 26 was the primary endpoint, except for PIONEER 7 where the primary endpoint was achievement of $\mathrm{HbA} \mathrm{A}_{1 \mathrm{C}}<7.0 \%$ (53 $\mathrm{mmol} / \mathrm{mol}$ ) at week 52. Estimated mean changes from baseline in $\mathrm{HbA}_{1 \mathrm{c}}$ are regardless of trial product discontinuation or rescue medication (treatment policy estimand). Oral semaglutide $3 \mathrm{mg}$ daily was also tested in PIONEER 1, PIONEER 3, and PIONEER 8; however, this dose is not recommended as a maintenance dose [Rybelsus SPC] and data are not shown (except for in PIONEER 7 as part of a flexible dosing approach in which investigators could increase or decrease the dose of oral semaglutide between 3,7 and 14 $\mathrm{mg}$ according to efficacy and tolerability criteria and clinical judgment). ${ }^{*} p<0.05$ for the estimated treatment difference with semaglutide vs. comparator. Cana, canagliflozin; dula, dulaglutide; empa, empagliflozin; $\mathrm{ER}$, extended release; exe, exenatide; $\mathrm{HbA}_{1 \mathrm{C}}$, glycated hemoglobin; IGlar, insulin glargine; lira, liraglutide; met, metformin; $\mathrm{N}$, number of randomized patients; pbo, placebo; s.c., subcutaneous; sema, semaglutide; SGLT2i, sodium-glucose co-transporter-2 inhibitor; sita, sitagliptin; SU, sulfonylurea; T2D, type 2 diabetes; TZD, thiazolidinedione.

semaglutide $(0.5 \mathrm{mg}$ and $1.0 \mathrm{mg})$ and oral semaglutide $(7 \mathrm{mg}$, $14 \mathrm{mg}$, and flexibly dosed) reduced body weight significantly more than sitagliptin (all $p<0.001$ ) (Figure 2B) $(17,29,33)$. When compared with other GLP-1RAs in patients with established T2D, subcutaneous semaglutide $1.0 \mathrm{mg}$ significantly reduced body weight more than once-weekly exenatide ER $2.0 \mathrm{mg}(-5.6 \mathrm{~kg}$ vs. $-1.9 \mathrm{~kg})$, once-weekly dulaglutide $1.5 \mathrm{mg}(-6.5 \mathrm{~kg}$ vs. $-3.0 \mathrm{~kg})$, and once-daily liraglutide $1.2 \mathrm{mg}(-5.8 \mathrm{~kg}$ vs. $-1.9 \mathrm{~kg})$ (all $p<0.001)$ (Figure 2B) $(18,22,25)$. Oral semaglutide $14 \mathrm{mg}$ reduced body weight significantly more than liraglutide $1.8 \mathrm{mg}$ in PIONEER 4 $(-4.4 \mathrm{~kg}$ vs. $-3.1 \mathrm{~kg} ; p<0.001)(30)$.

When added to SGLT2i background therapy, subcutaneous semaglutide $1.0 \mathrm{mg}$ reduced body weight by $4.7 \mathrm{~kg}$ compared with $0.9 \mathrm{~kg}$ with placebo $(p<0.001)$ in SUSTAIN 9 (24) (Figure 2C). When compared with SGLT2i as second-line therapy, subcutaneous semaglutide $1.0 \mathrm{mg}$ reduced body weight significantly more than canagliflozin $300 \mathrm{mg}$ at 52 weeks $(-5.3 \mathrm{~kg}$ vs. $-4.2 \mathrm{~kg} ; p<0.01$ ), while oral semaglutide $14 \mathrm{mg}$ produced similar 
body weight reductions as empagliflozin $25 \mathrm{mg}$ at 26 weeks $(-3.8 \mathrm{~kg}$ vs. $-3.7 \mathrm{~kg}$ ) (Figure 2C) $(23,28)$. In SUSTAIN 4, patients on one or two OADs who received subcutaneous semaglutide $1.0 \mathrm{mg}$ lost $5.2 \mathrm{~kg}$ compared with weight gain of $1.2 \mathrm{~kg}$ with insulin glargine after 30 weeks $(p<0.001)(19)$.

\section{Patients With Advanced T2D}

In advanced T2D, both subcutaneous semaglutide $(0.5 \mathrm{mg}$ and $1.0 \mathrm{mg}$ ) and oral semaglutide $(7 \mathrm{mg}$ and $14 \mathrm{mg}$ ) reduced body weight significantly more than placebo in patients inadequately controlled on insulin $(p<0.001)$ (Figure 2D) $(20,26)$. In PIONEER 5, patients with moderate renal impairment treated with oral semaglutide $14 \mathrm{mg}$ lost $3.4 \mathrm{~kg}$, while those on placebo lost $0.9 \mathrm{~kg}$ at 26 weeks $(p<0.001)$ (Figure 2D) (31).

\section{PATIENT-REPORTED OUTCOMES}

Patient-reported outcomes assess psychological aspects such as treatment satisfaction, patient wellbeing, health status, and quality of life to complement clinical outcomes and provide an understanding of the physical, social, and emotional impact of treatment regimens (36).
A

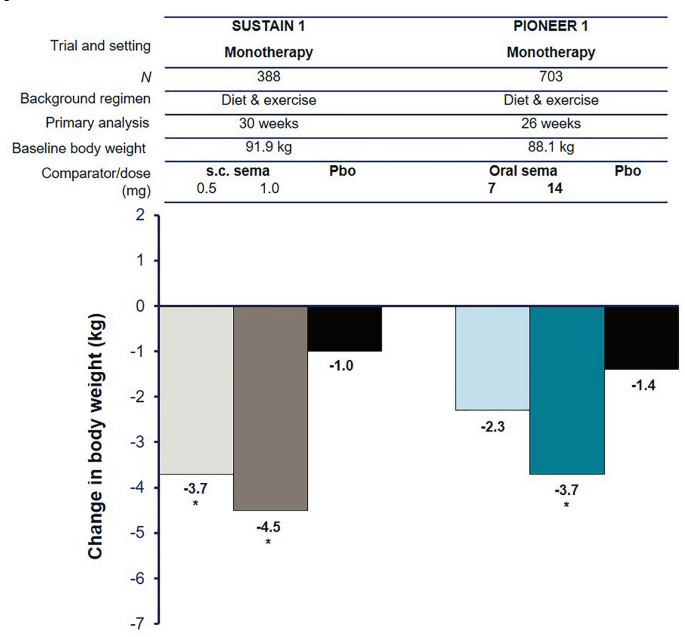

C
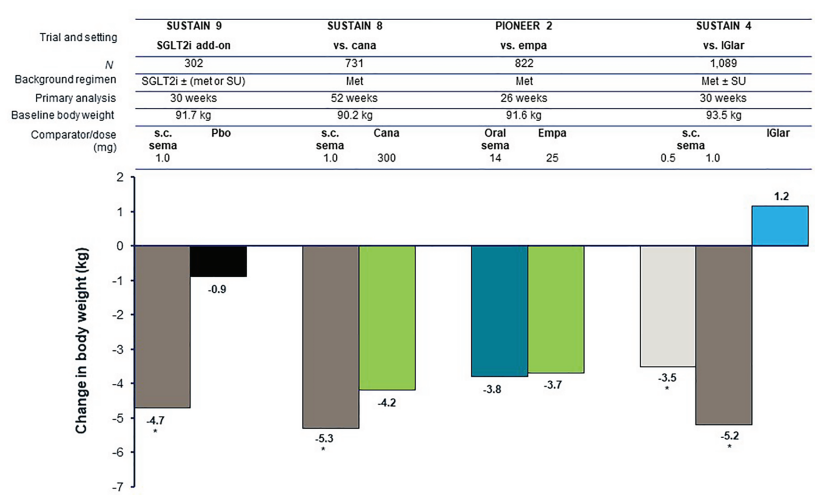

B
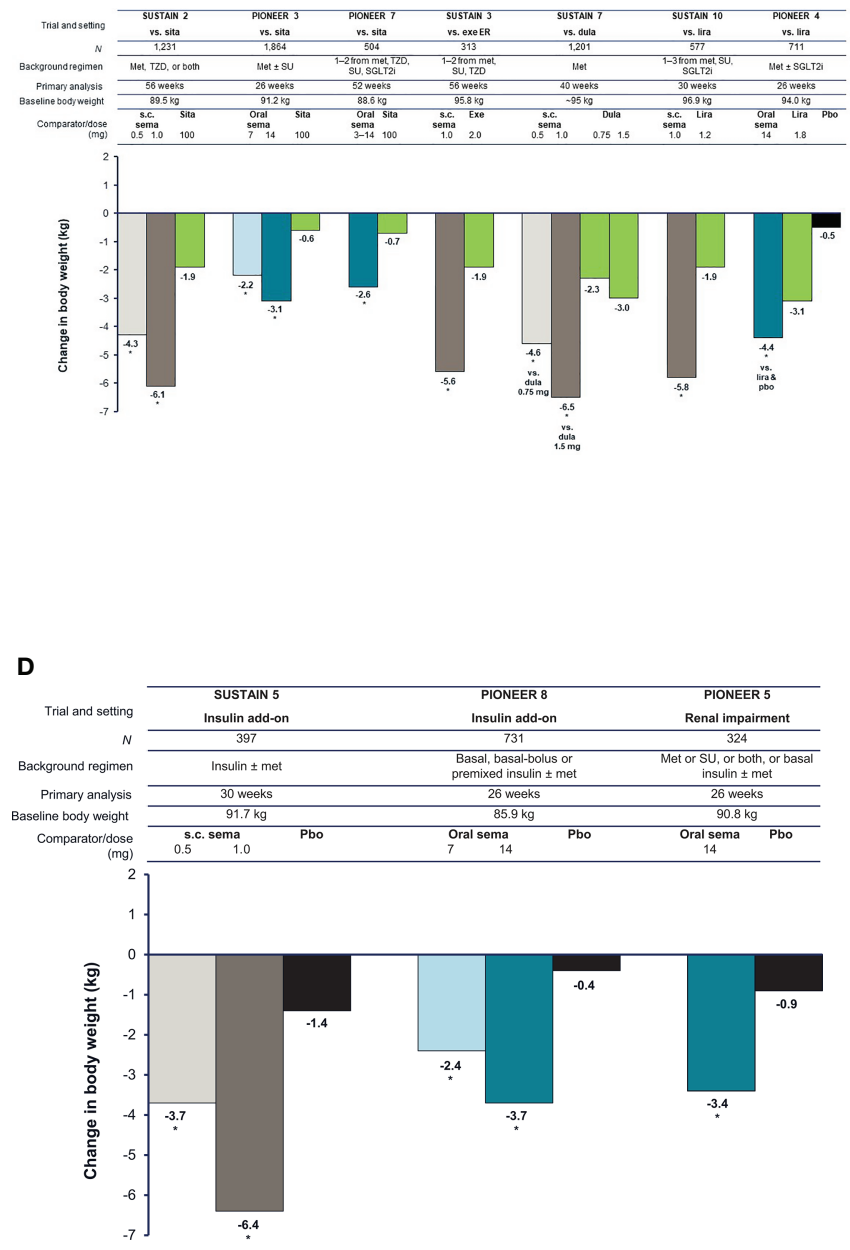

FIGURE 2 | Reduction in body weight with semaglutide and comparators (16-20, 22-26, 31, 33). (A) Trials in early T2D (3-4 years). (B) Trials in established T2D (6-10 years) with incretin-based therapies as comparators. (C) Trials in established T2D (6-10 years) with other comparators. (D) Trials in advanced T2D (13-15 years). For the SUSTAIN trials shown, estimated mean changes from baseline in body weight included only data obtained before initiation of any rescue medication or before premature treatment discontinuation. For the PIONEER trials shown, estimated mean changes from baseline in body weight are regardless of trial product discontinuation or rescue medication (treatment policy estimand). Oral semaglutide $3 \mathrm{mg}$ daily was also tested in PIONEER 1, PIONEER 3, and PIONEER 8; however, this dose is not recommended as a maintenance dose [Rybelsus SPC] and data are not shown (except for in PIONEER 7 as part of a flexible dosing approach in which investigators could increase or decrease the dose of oral semaglutide between 3,7 and $14 \mathrm{mg}$ according to efficacy and tolerability criteria and clinical judgment). ${ }^{*} p<0.05$ for the estimated treatment difference with semaglutide vs. comparator. Cana, canagliflozin; dula, dulaglutide; empa, empagliflozin; ER, extended release; exe, exenatide; IGlar, insulin glargine; lira, liraglutide; met, metformin; pbo, placebo; s.c., subcutaneous; sema, semaglutide; SGLT2i, sodium-glucose co-transporter-2 inhibitor; sita, sitagliptin; SU, sulfonylurea; T2D, type 2 diabetes; TZD, thiazolidinedione. 
When treatment satisfaction was measured by the Diabetes Treatment Satisfaction Questionnaire (DTSQ) in patients treated with subcutaneous semaglutide in SUSTAIN 2-5, improvements were significantly greater vs. comparators/placebo (all $p<0.05$ ) and were generally greater in patients who achieved vs. did not achieve weight loss and glycemic targets (37). In SUSTAIN 7, improvements in overall treatment satisfaction were generally similar between semaglutide and dulaglutide, irrespective of weight loss or glycemic control.

When the DTSQ was used in PIONEER 4, 7, and 8, total treatment satisfaction scores with oral semaglutide were similar to active comparators and better than with placebo (except in PIONEER 5 in which scores for oral semaglutide and placebo were similar) $(26,30,31,33)$. In PIONEER 4, DTSQ scores favored oral semaglutide over placebo for all items at weeks 26 and 52 except 'feeling of unacceptably low blood sugars' (weeks 26 and 52) and 'flexibility of treatment' (week 52), which were similar (30). There were no differences in treatment satisfaction between oral semaglutide and liraglutide $1.8 \mathrm{mg}$.

In PIONEER 7, change from baseline to week 52 in DTSQ scores for satisfaction with treatment, convenience and flexibility of treatment, and total treatment satisfaction appeared similar for oral semaglutide and sitagliptin despite the specific dosing instructions needed with oral semaglutide (33). In PIONEER 5 and 8 in advanced T2D, the frequency of patient-perceived hyperglycemia was significantly lower in the oral semaglutide group than in the placebo group $(26,31)$.

The 36-item Short-Form Survey (SF-36) version 2 was used to assess physical function, pain, general health, mental health, emotional function, and social function in SUSTAIN 2, 4, and 7 (17, 19, 22). In SUSTAIN 2, several aspects on the SF-36 improved with subcutaneous semaglutide vs. sitagliptin and none worsened (17). In SUSTAIN 4, subcutaneous semaglutide $1.0 \mathrm{mg}$ demonstrated significant improvement compared with insulin glargine in the role-emotional (measure of role limitations due to emotional problems) and general health domains of the SF-36, but not in other domains (19). In SUSTAIN 7, SF-36 scores were similar between subcutaneous semaglutide and dulaglutide (22).

SF-36 version 2 scores were similar between oral semaglutide and sitagliptin in PIONEER 3 and PIONEER 7 (29, 33). In PIONEER 2, scores using the SF-36 were broadly similar with oral semaglutide $14 \mathrm{mg}$ and empagliflozin $25 \mathrm{mg}$; however, scores were significantly better for oral semaglutide than empagliflozin for the domains of general health and social functioning at week 26, but favored empagliflozin for the rolephysical domain and physical component summary scores at week 52 (28). In patients with renal impairment in PIONEER 5, SF-36 scores at week 26 significantly favored oral semaglutide over placebo for the physical component summary and the rolephysical, bodily pain, and social functioning domains (31).

For patients with more advanced disease in PIONEER 8, oral semaglutide $14 \mathrm{mg}$ significantly improved general health at week 52 and mental health at week 26 compared with placebo (26). Furthermore, significant improvements in the psychosocial domain and total score of the Impact of Weight on Quality of
Life-Lite Clinical Trial Version were observed with oral semaglutide $14 \mathrm{mg}$ vs. placebo at weeks 26 and 52.

\section{EXPOSURE-RESPONSE RELATIONSHIPS}

In pharmacokinetic studies, lower bioavailability with oral administration of semaglutide appeared to result in more variable plasma concentrations compared with subcutaneous administration $(38,39)$. Using data from the SUSTAIN and PIONEER trials, population pharmacokinetic and exposureresponse analyses were used to investigate if the oral route of administration changed the efficacy and tolerability of semaglutide compared with subcutaneous administration (39). Exposure-response analyses showed greater $\mathrm{HbA}_{1 \mathrm{c}}$ reductions with increasing semaglutide exposure and the same relationship was observed with body weight reductions. The exposure range with oral semaglutide was found to be wider than for subcutaneous semaglutide, consistent with the more variable plasma concentrations with oral treatment, but there was considerable overlap between oral semaglutide 7 and $14 \mathrm{mg}$ and subcutaneous semaglutide 0.5 and $1.0 \mathrm{mg}$. The authors concluded that similar exposure-response relationships were observed for efficacy $\left(\mathrm{HbA}_{1 \mathrm{c}}\right.$ and body weight) and also for tolerability (nausea and vomiting) of semaglutide, regardless of the route of administration.

\section{SELECTION OF THE MOST APPROPRIATE FORMULATION}

With the efficacy of both formulations established and approval granted, healthcare professionals and patients are in a position to choose the formulation that best suits the needs of the individual patient (Figure 3).

Regarding efficacy, a network meta-analysis showed that once-daily oral semaglutide $14 \mathrm{mg}$ was associated with numerically greater $\mathrm{HbA}_{1 \mathrm{c}}$ reductions than once-weekly subcutaneous semaglutide $0.5 \mathrm{mg}$ and also dulaglutide $1.5 \mathrm{mg}$ and liraglutide $1.8 \mathrm{mg}$ (40). No statistical difference in efficacy was observed between oral semaglutide $14 \mathrm{mg}$ and once-weekly subcutaneous semaglutide $1.0 \mathrm{mg}$ at week 26, although $\mathrm{HbA}_{1 \mathrm{c}}$ reductions were numerically greater with subcutaneous semaglutide $1.0 \mathrm{mg}$. Oral semaglutide provided a significantly greater reduction in body weight than all GLP-1RA comparators studied except subcutaneous semaglutide $0.5 \mathrm{mg}$ and $1.0 \mathrm{mg}$ (40). No head-to-head studies have compared approved doses of oral semaglutide ( $7 \mathrm{mg}$ and $14 \mathrm{mg}$ ) vs. once-weekly subcutaneous semaglutide $(0.5 \mathrm{mg}$ and $1.0 \mathrm{mg})$. Doses of oral semaglutide of $2.5 \mathrm{mg}, 5 \mathrm{mg}, 10 \mathrm{mg}, 20 \mathrm{mg}$, and $40 \mathrm{mg}$ were studied in the phase II trial (41). The phase II trial included an arm in which patients received subcutaneous semaglutide $1.0 \mathrm{mg}$; however, the primary endpoint of glycemic efficacy was only statistically significant compared with placebo, not between active oral vs. injectable treatment groups (41). In the exposure analyses, average exposure for once-weekly subcutaneous 


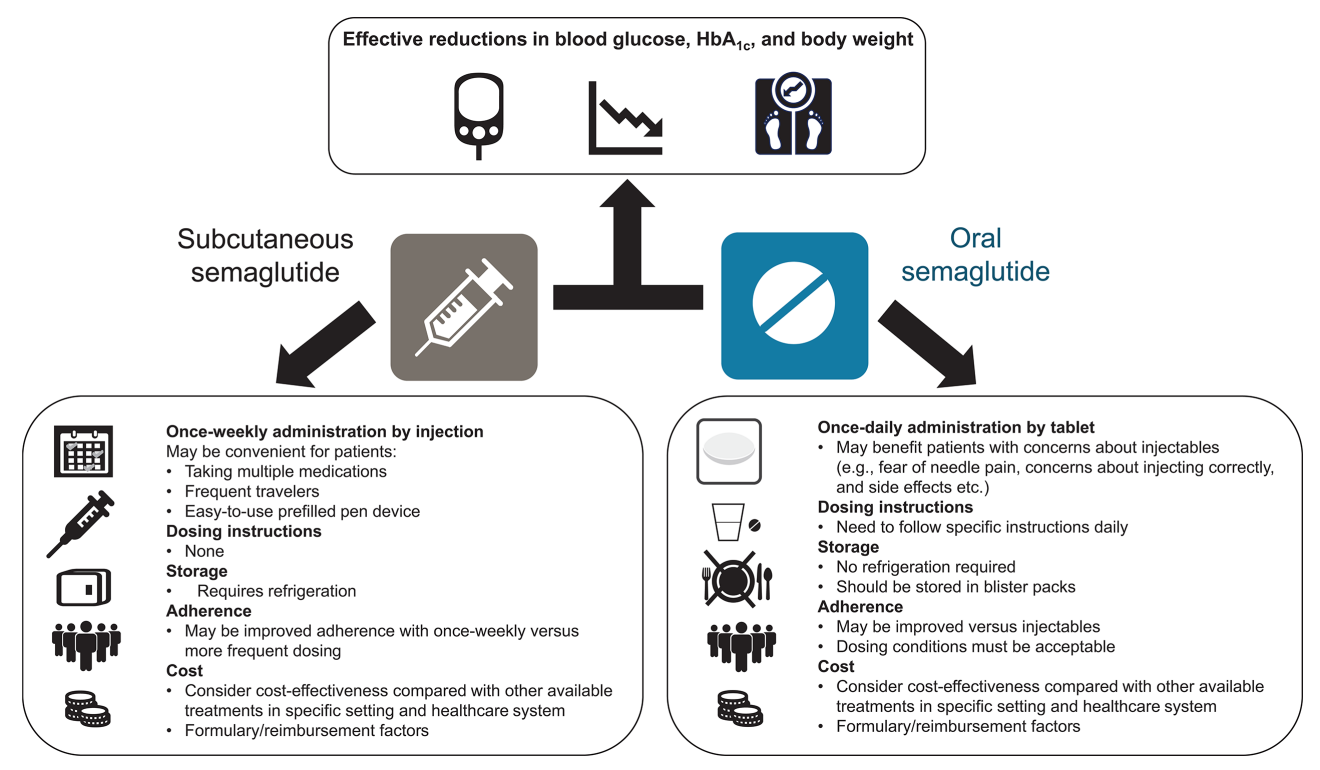

FIGURE 3 | Overview of considerations related to the use of subcutaneous and oral formulations of semaglutide. $\mathrm{HbA}_{1 \mathrm{c}}$, glycated hemoglobin.

semaglutide $1.0 \mathrm{mg}$ was higher than with oral semaglutide $14 \mathrm{mg}$, but as mentioned, the exposure range with oral semaglutide was wider than for subcutaneous dosing, with a considerable overlap between oral semaglutide 7 and $14 \mathrm{mg}$ and subcutaneous semaglutide 0.5 and $1.0 \mathrm{mg}$ (39).

As discussed in detail in (15), the risk of hypoglycemia is low with both formulations of semaglutide, despite the effective $\mathrm{HbA}_{1 \mathrm{c}}$ reductions $(16-20,22-31,33)$, which may be due to the glucose-dependent mechanism of action of GLP-1RAs. The safety profile is very similar for both formulations (16-20, 22$31,33)$. Injection-site reactions are uncommon with the subcutaneous formulation (18). Subcutaneous semaglutide has proven cardiovascular benefit (21); this has not been demonstrated for oral semaglutide, although cardiovascular safety has been shown $(32,34)$.

Given the generally similar efficacy and safety profiles of the two formulations, other considerations may need to be taken into account when selecting the most appropriate formulation to use. Many patients are reluctant to initiate injectable treatment and barriers to their use include fear of injection pain, feelings of failure related to disease progression, embarrassment/concerns about injecting in public, being nervous about injecting correctly, and adverse events $(42,43)$. Physicians may also be reluctant to start injectable therapy due to concerns over patient adherence, perceived fear of injection pain, and lack of knowledge of newer therapies (44). For patients who are reluctant to initiate injectable therapy and have a preference for oral administration, oral semaglutide may represent the more appropriate choice. However, the effective use of oral semaglutide depends on the patient following certain dosing instructions. Patients are instructed to swallow the oral semaglutide tablet whole on waking and on an empty stomach, with a sip of water (up to half a glass of water equivalent to $120 \mathrm{~mL}$ ), and to wait at least
30 minutes before eating, drinking, or taking other oral medications that day $(13,14)$. The beneficial effects of oral semaglutide may be attenuated if this guidance is not followed.

In a survey for more than 500 patients presented with hypothetical drug profiles, a greater proportion of respondents preferred a once-daily oral treatment with fewer dosing requirements, similar to empagliflozin $(41 \%)$ or sitagliptin $(31 \%)$, than a profile corresponding to that of oral semaglutide (11\%), citing factors such as fasting and potential gastrointestinal effects (45). However, in an actual clinical trial setting (PIONEER 7), patient-reported satisfaction and treatment convenience were similar between oral semaglutide and sitagliptin (33). Another survey of 600 patients compared preferences regarding once-daily oral semaglutide and a once-weekly injectable GLP-1RA. Three times as many patients preferred the oral to the injectable treatment when initially asked ( $77 \%$ vs $24 \%$ ), but after they were given more detail on the actual dosing requirements, just over half of respondents indicated a preference for oral semaglutide (46). However, preferences may vary according to factors such as geographical region. For example, a survey of Japanese patients $(n=500)$ found that approximately $90 \%$ of patients preferred the profile of once-daily oral semaglutide to that of once-weekly injectable dulaglutide (47).

Some patients may prefer the less frequent once-weekly administration of subcutaneous semaglutide over the need to take a tablet with specific dosing instructions each morning, e.g., those with multiple concomitant medications. Patients generally report a preference for less frequent dosing with injectable GLP-1RAs (48-51), and adherence and persistence rates are improved with once-weekly injectable GLP-1RAs compared with more frequently dosed treatments (52-56). In addition, the subcutaneous version of semaglutide might be preferred for patients prescribed levothyroxine, which should itself be taken 
in the morning on an empty stomach, half an hour before breakfast (57). The use of an injection pen may also be considered more convenient and less burdensome than the need for daily tablets by some patients, e.g., those who travel frequently. The subcutaneous formulation requires refrigeration, unlike tablets, which may be a factor for some patients.

Cost-effectiveness is also likely to be a consideration. The relative cost-effectiveness of the two semaglutide formulations has not been directly compared. However, both subcutaneous and oral semaglutide have been reported to be more costeffective and offer lower cost-of-control compared with other injectable GLP-1RAs and oral glucose-lowering drugs, although this may vary between different patient cohorts and healthcare settings (58-64). In addition, switching may be dependent on non-medical decisions outwith the physician's choice, with a recent expert consensus indicating that non-medical triggers for switching to subcutaneous semaglutide from other GLP-1RAs also included formulary changes and insurance mandates, as well as cost considerations (65).

To conclude, when treatment intensification is needed to improve glycemic control, semaglutide offers the benefits of an effective GLP-1RA in both an injectable and an oral formulation.

\section{REFERENCES}

1. Stratton IM, Adler AI, Neil HA, Matthews DR, Manley SE, Cull CA, et al. Association of glycaemia with macrovascular and microvascular complications of type 2 diabetes (UKPDS 35): prospective observational study. BMJ (2000) 321:405-12. doi: 10.1136/ bmj.321.7258.405

2. Laiteerapong N, Ham SA, Gao Y, Moffet HH, Liu JY, Huang ES, et al. The legacy effect in type 2 diabetes: impact of early glycemic control on future complications (the Diabetes \& Aging Study). Diabetes Care (2019) 42:416-26. doi: $10.2337 / \mathrm{dc} 17-1144$

3. An J, Nichols GA, Qian L, Harrison TN, Li Z, Munis MA, et al. Time in suboptimal glycemic control over 10 years for patients newly diagnosed with type 2 diabetes. J Diabetes Complicat (2020) 34:107607. doi: 10.1016/ j.jdiacomp.2020.107607

4. Davies MJ, D’Alessio DA, Fradkin J, Kernan WN, Mathieu C, Mingrone G, et al. Management of hyperglycemia in type 2 diabetes, 2018. A consensus report by the American Diabetes Association (ADA) and the European Association for the Study of Diabetes (EASD). Diabetes Care (2018) 41:2669-701. doi: 10.2337/dci18-0033

5. Davies MJ, Bianchi C, Del Prato S. Use of incretin-based medications: what do current international recommendations suggest with respect to GLP-1 receptor agonists and DPP-4 inhibitors? Metabolism (2020) 107:154242. doi: $10.1016 /$ j.metabol.2020.154242

6. Meier JJ. GLP-1 receptor agonists for individualized treatment of type 2 diabetes mellitus. Nat Rev Endocrinol (2012) 8:728-42. doi: 10.1038/nrendo.2012.140

7. Nauck MA, Meier JJ. Management of endocrine disease: are all GLP-1 agonists equal in the treatment of type 2 diabetes? Eur J Endocrinol (2019) 181:R211-34. doi: 10.1530/EJE-19-0566

8. DeFronzo RA, Triplitt CL, Abdul-Ghani M, Cersosimo E. Novel agents for the treatment of type 2 diabetes. Diabetes Spectr (2014) 27:100-12. doi: $10.2337 /$ diaspect.27.2.100

9. Romera I, Cebrián-Cuenca A, Álvarez-Guisasola F, Gomez-Peralta F, Reviriego J. A review of practical issues on the use of glucagon-like peptide-1 receptor agonists for the management of type 2 diabetes. Diabetes Ther (2019) 10:5-19. doi: 10.1007/s13300-018-0535-9
Selection of the most appropriate formulation can be made on an individual basis to best suit the patient's preferences and needs.

\section{AUTHOR CONTRIBUTIONS}

The author was involved with drafting and/or critically reviewing all drafts during the development of the article, and provided final approval for submission.

\section{FUNDING}

This article was supported by Novo Nordisk, who was provided with the opportunity to perform a medical accuracy review.

\section{ACKNOWLEDGMENTS}

Under the direction of the author, medical writing and editorial support were provided by Andy Bond of Axis, a division of Spirit Medical Communications Group Limited (funded by Novo Nordisk).

10. Nauck MA, Meier JJ. Pioneering oral peptide therapy for patients with type 2 diabetes. Lancet Diabetes Endocrinol (2019) 7:500-2. doi: 10.1016/S2213-8587 (19)30182-2

11. Food and Drug Administration. Ozempic ${ }^{\circledR}$ Prescribing Information. Available at: https://www.accessdata.fda.gov/drugsatfda_docs/label/2017/209637lbl.pdf (Accessed September 15, 2020).

12. European Medicines Agency. Ozempic ${ }^{\circledR}$ Summary of Product Characteristics. Available at: https://www.ema.europa.eu/en/documents/product-information/ ozempic-epar-product-information_en.pdf (Accessed September 15, 2020).

13. Food and Drug Administration. Rybelsus ${ }^{\circledR}$ Prescribing Information. Available at: https://www.accessdata.fda.gov/drugsatfda_docs/label/2019/ 213051s000lbl.pdf (Accessed September 15, 2020).

14. European Medicines Agency. Rybelsus ${ }^{\circledR}$ Summary of Product Characteristics. Available at: https://www.ema.europa.eu/en/documents/productinformation/rybelsus-epar-product-information_en.pdf (Accessed December 10, 2020)

15. Smits MM, Van Raalte DH. Safety of semaglutide. [Suppl article].

16. Sorli C, Harashima SI, Tsoukas GM, Unger J, Karsbøl JD, Hansen T, et al. Efficacy and safety of once-weekly semaglutide monotherapy versus placebo in patients with type 2 diabetes (SUSTAIN 1): a double-blind, randomised, placebo-controlled, parallel-group, multinational, multicentre phase $3 \mathrm{a}$ trial. Lancet Diabetes Endocrinol (2017) 5:251-60. doi: 10.1016/S2213-8587(17) 30013-X

17. Ahrén B, Masmiquel L, Kumar H, Sargin M, Karsbøl JD, Jacobsen SH, et al. Efficacy and safety of once-weekly semaglutide versus once-daily sitagliptin as an add-on to metformin, thiazolidinediones, or both, in patients with type 2 diabetes (SUSTAIN 2): a 56-week, double-blind, phase 3a, randomised trial. Lancet Diabetes Endocrinol (2017) 5:341-54. doi: 10.1016/S2213-8587(17) 30092-X

18. Ahmann AJ, Capehorn M, Charpentier G, Dotta F, Henkel E, Lingvay I, et al. Efficacy and safety of once-weekly semaglutide versus exenatide ER in subjects with type 2 diabetes (SUSTAIN 3): a 56-week, open-label, randomized clinical trial. Diabetes Care (2018) 41:258-66. doi: 10.2337/dc17-0417

19. Aroda VR, Bain SC, Cariou B, Piletič M, Rose L, Axelsen M, et al. Efficacy and safety of once-weekly semaglutide versus once-daily insulin glargine as add-on to metformin (with or without sulfonylureas) in insulin-naive patients with type 2 diabetes (SUSTAIN 4): a randomised, open-label, parallel-group, 
multicentre, multinational, phase 3a trial. Lancet Diabetes Endocrinol (2017) 5:355-66. doi: 10.1016/S2213-8587(17)30085-2

20. Rodbard HW, Lingvay I, Reed J, de la Rosa R, Rose L, Sugimoto D, et al. Semaglutide added to basal insulin in type 2 diabetes (SUSTAIN 5): a randomized, controlled trial. J Clin Endocrinol Metab (2018) 103:2291-301. doi: 10.1210/jc.2018-00070

21. Marso SP, Bain SC, Consoli A, Eliaschewitz FG, Jódar E, Leiter LA, et al. Semaglutide and cardiovascular outcomes in patients with type 2 diabetes. N Engl J Med (2016) 375:1834-44. doi: 10.1056/NEJMoa1607141

22. Pratley RE, Aroda VR, Lingvay I, Lüdemann J, Andreassen C, Navarria A, et al. Semaglutide versus dulaglutide once weekly in patients with type 2 diabetes (SUSTAIN 7): a randomised, open-label, phase 3b trial. Lancet Diabetes Endocrinol (2018) 6:275-86. doi: 10.1016/S2213-8587(18)30024-X

23. Lingvay I, Catarig AM, Frias JP, Kumar H, Lausvig NL, le Roux CW, et al. Efficacy and safety of once-weekly semaglutide versus daily canagliflozin as add-on to metformin in patients with type 2 diabetes (SUSTAIN 8): a doubleblind, phase 3b, randomised controlled trial. Lancet Diabetes Endocrinol (2019) 7:834-44. doi: 10.1016/S2213-8587(19)30311-0

24. Zinman B, Bhosekar V, Busch R, Holst I, Ludvik B, Thielke D, et al. Semaglutide once weekly as add-on to SGLT-2 inhibitor therapy in type 2 diabetes (SUSTAIN 9): a randomised, placebo-controlled trial. Lancet Diabetes Endocrinol (2019) 7:356-67. doi: 10.1016/S2213-8587(19)30066-X

25. Capehorn MS, Catarig AM, Furberg JK, Janez A, Price HC, Tadayon S, et al. Efficacy and safety of once-weekly semaglutide $1.0 \mathrm{mg}$ vs once-daily liraglutide $1.2 \mathrm{mg}$ as add-on to 1-3 oral antidiabetic drugs in subjects with type 2 diabetes (SUSTAIN 10). Diabetes Metab (2020) 46:100-9. doi: 10.1016/ j.diabet.2019.101117

26. Zinman B, Aroda VR, Buse JB, Cariou B, Harris SB, Hoff ST, et al. Efficacy, safety and tolerability of oral semaglutide versus placebo added to insulin \pm metformin in patients with type 2 diabetes: the PIONEER 8 trial. Diabetes Care (2019) 42:2262-71. doi: 10.2337/dc19-0898

27. Aroda VR, Rosenstock J, Terauchi Y, Altuntas Y, Lalic NM, Morales Villegas EC, et al. PIONEER 1: randomized clinical trial of the efficacy and safety of oral semaglutide monotherapy in comparison with placebo in patients with type 2 diabetes. Diabetes Care (2019) 42:1724-32. doi: 10.2337/dc19-0749

28. Rodbard HW, Rosenstock J, Canani LH, Deerochanawong C, Gumprecht J, Lindberg $>\mathrm{S} \emptyset$, et al. Oral semaglutide versus empagliflozin in patients with type 2 diabetes uncontrolled on metformin: the PIONEER 2 trial. Diabetes Care (2019) 42:2272-81. doi: 10.2337/dc19-0883

29. Rosenstock J, Allison D, Birkenfeld AL, Blicher TM, Deenadayalan S, Jacobsen JB, et al. Effect of additional oral semaglutide vs sitagliptin on glycated hemoglobin in adults with type 2 diabetes uncontrolled with metformin alone or with sulfonylurea: the PIONEER 3 randomized clinical trial. JAMA (2019) 321:1466-80. doi: 10.1001/jama.2019.2942

30. Pratley R, Amod A, Tetens Hoff S, Kadowaki T, Lingvay I, Nauck M, et al. Oral semaglutide versus subcutaneous liraglutide and placebo in type 2 diabetes (PIONEER 4): a randomised, double-blind, phase 3a trial. Lancet (2019) 394:39-50. doi: 10.1016/S0140-6736(19)31271-1

31. Mosenzon O, Blicher TM, Rosenlund S, Eriksson JW, Heller S, Hels OH, et al. Efficacy and safety of oral semaglutide in patients with type 2 diabetes and moderate renal impairment (PIONEER 5): a placebo-controlled, randomised, phase 3a trial. Lancet Diabetes Endocrinol (2019) 7:515-27. doi: 10.1016/ S2213-8587(19)30192-5

32. Husain M, Birkenfeld AL, Donsmark M, Dungan K, Eliaschewitz FG, Franco DR, et al. Oral semaglutide and cardiovascular outcomes in patients with type 2 diabetes. N Engl J Med (2019) 381:841-51. doi: 10.1056/NEJMoa1901118

33. Pieber TR, Bode B, Mertens A, Cho YM, Christiansen E, Hertz CL, et al. Efficacy and safety of oral semaglutide with flexible dose adjustment versus sitagliptin in type 2 diabetes (PIONEER 7): a multicentre, open-label, randomised, phase 3a trial. Lancet Diabetes Endocrinol (2019) 7:528-39. doi: 10.1016/S2213-8587(19)30194-9

34. Nauck MA, Quast DR. Cardiovascular safety and benefits of semaglutide in patients with type 2 diabetes: findings from SUSTAIN 6 and PIONEER 6 [Suppl article].

35. Aroda VR, Saugstrup T, Buse JB, Donsmark M, Zacho J, Davies MJ. Incorporating and interpreting regulatory guidance on estimands in diabetes clinical trials: the PIONEER 1 randomized clinical trial as an example. Diabetes Obes Metab (2019) 21:2203-10. doi: 10.1111/dom.13804
36. Jendle J, Birkenfeld AL, Polonsky WH, Silver R, Uusinarkaus K, Hansen T, et al. Improved treatment satisfaction in patients with type 2 diabetes treated with once-weekly semaglutide in the SUSTAIN trials. Diabetes Obes Metab (2019) 21:2315-26. doi: 10.1111/dom.13816

37. Marrero DG, Hilliard ME, Maahs DM, McAuliffe-Fogarty AH, Hunter CM. Using patient reported outcomes in diabetes research and practice: recommendations from a national workshop. Diabetes Res Clin Pract (2019) 153:23-9. doi: 10.1016/j.diabres.2019.05.016

38. Granhall C, Donsmark M, Blicher TM, Golor G, Søndergaard FL, Thomsen $\mathrm{M}$, et al. Safety and pharmacokinetics of single and multiple ascending doses of the novel oral human GLP-1 analogue, oral semaglutide, in healthy subjects and subjects with type 2 diabetes. Clin Pharmacokinet (2019) 58:781-91. doi: 10.1007/s40262-018-0728-4

39. Overgaard RV, Navarria A, Hertz CL, Ingwersen SH. Similar efficacy and gastrointestinal tolerability versus exposure for oral and subcutaneous semaglutide. Presented at the 55th Annual Meeting of the European Association for the Study of Diabetes. September 17-20, 2019. Barcelona, Spain, Abstract \#777.

40. Nuhoho S, Gupta J, Hansen BB, Fletcher-Louis M, Dang-Tan T, Paine A. Orally administered semaglutide versus GLP-1 RAs in patients with type 2 diabetes previously receiving 1-2 oral antidiabetics: systematic review and network meta-analysis. Diabetes Ther (2019) 10:2183-99. doi: 10.1007/ s13300-019-00706-y

41. Davies M, Pieber TR, Hartoft-Nielsen ML, Hansen OKH, Jabbour S, Rosenstock J. Effect of oral semaglutide compared with placebo and subcutaneous semaglutide on glycemic control in patients with type 2 diabetes: a randomized clinical trial. JAMA (2017) 318:1460-70. doi: 10.1001/jama.2017.14752

42. Spain CV, Wright JJ, Hahn RM, Wivel A, Martin AA. Self-reported barriers to adherence and persistence to treatment with injectable medications for type 2 diabetes. Clin Ther (2016) 38:1653-64. doi: 10.1016/j.clinthera.2016.05.009

43. Brod M, Alolga SL, Meneghini L. Barriers to initiating insulin in type 2 diabetes patients: development of a new patient education tool to address myths, misconceptions and clinical realities. Patient (2014) 7:437-50. doi: 10.1007/s40271-014-0068-x

44. Khunti K, Millar-Jones D. Clinical inertia to insulin initiation and intensification in the UK: a focused literature review. Prim Care Diabetes (2017) 11:3-12. doi: 10.1016/j.pcd.2016.09.003

45. Savarese G, Sharma A, Pang C, Wood R, George JT, Soleymanlou N. Patient preferences for newer oral therapies in type 2 diabetes. Diabetes (2020) 69 (Suppl 1). doi: 10.2337/db20-2216-PUB

46. Boye K, Ross M, Mody R, Konig M, Gelhorn H. Patients' preferences for oncedaily oral versus once-weekly injectable diabetes medications: the REVISE study. Diabetes Obes Metab (2020) 23(2):508-19. doi: 10.1111/dom.14244

47. Igarashi A, Hansen BB, Langer J, Tavella F, Collings H, Davies N, et al. Preference for oral and injectable GLP-1RA therapy profiles in Japanese patients with type 2 diabetes: a discrete choice experiment. Adv Ther (2020) 38:721-38. doi: 10.1007/s12325-020-01561-1

48. Hauber AB, Nguyen H, Posner J, Kalsekar I, Ruggles J. A discrete-choice experiment to quantify patient preferences for frequency of glucagon-like peptide-1 receptor agonist injections in the treatment of type 2 diabetes. Curr Med Res Opin (2016) 32(2):251-62. doi: 10.1185/03007995.2015.1117433

49. Thieu VT, Robinson S, Kennedy-Martin T, Boye KS, Garcia-Perez LE. Patient preferences for glucagon-like peptide 1 receptor-agonist treatment attributes. Patient Prefer Adherence (2019) 13:561-76. doi: 10.2147/PPA.S187907

50. Suzuki S, Oura T, Takeuchi M, Boye KS. Evaluation of the impact of once weekly dulaglutide on patient-reported outcomes in Japanese patients with type 2 diabetes: comparisons with liraglutide, insulin glargine, and placebo in two randomized studies. Health Qual Life Outcomes (2017) 15(1):123. doi: 10.1186/s12955-017-0696-7

51. Takase T, Nakamura A, Yamamoto C, Nomoto H, Miya A, Dannoura M, et al. Improvement in treatment satisfaction after switching from liraglutide to dulaglutide in patients with type 2 diabetes: a randomized controlled trial. J Diabetes Investig (2019) 10(3):699-705. doi: 10.1111/jdi.12906

52. Qiao Q, Ouwens MJ, Grandy S, Johnsson K, Kostev K. Adherence to GLP1RA therapy administered by once-daily or once-weekly injection in patients with type 2 diabetes in Germany. Diabetes Metab Syndr Obes (2016) 9:201-5. doi: 10.2147/DMSO.S99732 
53. Nguyen H, Dufour R, Caldwell-Tarr A, Nomoto H, Miya A, Dannoura M. Glucagon-like peptide-1 receptor agonist (GLP-1RA) therapy adherence for patients with type 2 diabetes in a medicare population. Adv Ther (2017) 34 (3):658-73. doi: 10.1007/s12325-016-0470-y

54. Alatorre C, Fernández Landó L, Yu M, Brown K, Montejano L, Juneau P, et al. Treatment patterns in patients with type 2 diabetes mellitus treated with glucagon-like peptide-1 receptor agonists: higher adherence and persistence with dulaglutide compared with once-weekly exenatide and liraglutide. Diabetes Obes Metab (2017) 19(7):953-61. doi: 10.1111/dom.12902

55. Federici MO, McQuillan J, Biricolti G, Losi S, Lebrec J, Richards C, et al. Utilization patterns of glucagon-like peptide-1 receptor agonists in patients with type 2 diabetes mellitus in Italy: a retrospective cohort study. Diabetes Ther (2018) 9(2):789-801. doi: 10.1007/s13300-018-0396-2

56. Otto T, Myland M, Jung H, Lebrec J, Richter H, Norrbacka K. Utilization patterns of glucagon-like peptide- 1 receptor agonists in patients with type 2 diabetes mellitus in Germany: a retrospective cohort study. Curr Med Res Opin (2019) 35(5):893-901. doi: 10.1080/03007995.2018.1538011

57. Merck. Euthyrox Summary of Product Characteristics (2017). Available at: https://mri.cts-mrp.eu/Human/Downloads/DE_H_0284_004_FinalSPC_ 1of2.pdf (Accessed June 29, 2020).

58. Gæde P, Johansen P, Tikkanen CK, Pollock RF, Hunt B, Malkin SJP. Management of patients with type 2 diabetes with once-weekly semaglutide versus dulaglutide, exenatide ER, liraglutide and lixisenatide: a costeffectiveness analysis in the Danish setting. Diabetes Ther (2019) 10 (4):1297-317. doi: 10.1007/s13300-019-0630-6

59. Johansen P, Chubb B, Hunt B, Malkin SJP, Sandberg A, Capehorn M. Evaluating the long-term cost-effectiveness of once-weekly semaglutide versus once-daily liraglutide for the treatment of type 2 diabetes in the UK. Adv Ther (2020) 37(5):2427-41. doi: 10.1007/s12325-020-01337-7

60. Martín V, Vidal J, Malkin SJP, Hallén N, Hunt B. Evaluation of the long-term cost-effectiveness of once-weekly semaglutide versus dulaglutide and sitagliptin in the Spanish setting. Adv Ther (2020) 37(10):4427-45. doi: 10.1007/s12325-020-01464-1

61. Johansen P, Hunt B, Iyer NN, Dang-Tan T, Pollock RF. A relative cost of control analysis of once-weekly semaglutide versus exenatide extendedrelease and dulaglutide for bringing patients to $\mathrm{HbAlc}$ and weight loss treatment targets in the USA. Adv Ther (2019) 36(5):1190-9. doi: 10.1007/ s12325-019-00915-8

62. Hansen BB, Nuhoho S, Ali SN, Dang-Tan T, Valentine WJ, Malkin SJP, et al. Oral semaglutide versus injectable glucagon like peptide-1 receptor agonists: a cost of control analysis. J Med Econ (2020) 23(6):650-8. doi: 10.1080/ 13696998.2020.1722678

63. Bain SC, Hansen BB, Malkin SJP, Nuhoho S, Valentine WJ, Chubb B, et al. Oral semaglutide versus empagliflozin, sitagliptin and liraglutide in the UK: long-term cost-effectiveness analyses based on the PIONEER clinical trial programme. Diabetes Ther (2020) 11(1):259-77. doi: 10.1007/s13300-01900736-6

64. Hunt B, Hansen BB, Ericsson Å, Kallenbach K, Ali SN, Dang-Tan T, et al. Evaluation of the cost per patient achieving treatment targets with oral semaglutide: a short-term cost-effectiveness analysis in the United States. $A d v$ Ther (2019) 36(12):3483-93. doi: 10.1007/s12325-019-01125-y

65. Jain AB, Ali A, Gorgojo Martínez JJ, Hramiak I, Kavia K, Madsbad S, et al. Switching between GLP-1 receptor agonists in clinical practice: expert consensus and practical guidance. Int J Clin Pract (2021) 75(2):e13731. doi: $10.1111 /$ ijcp. 13731

Conflict of Interest: JJM has received lecture honoraria and consulting fees from AstraZeneca, Berlin-Chemie, Boehringer Ingelheim, Eli Lilly, Merck Sharp \& Dohme (MSD), Novartis, Novo Nordisk, and Sanofi; has received reimbursement of congress participation fees and travel expenses from MSD, Novo Nordisk, and Sanofi; and has initiated projects supported by Boehringer Ingelheim, MSD, Novo Nordisk, and Sanofi.

The author declares that this article received funding from Novo Nordisk. The funder had the following involvement in the article: medical writing support.

Copyright (C) 2021 Meier. This is an open-access article distributed under the terms of the Creative Commons Attribution License (CC BY). The use, distribution or reproduction in other forums is permitted, provided the original author(s) and the copyright owner(s) are credited and that the original publication in this journal is cited, in accordance with accepted academic practice. No use, distribution or reproduction is permitted which does not comply with these terms. 